\title{
Sangre, nobleza y poder en los comienzos del Virreinato de Nueva España

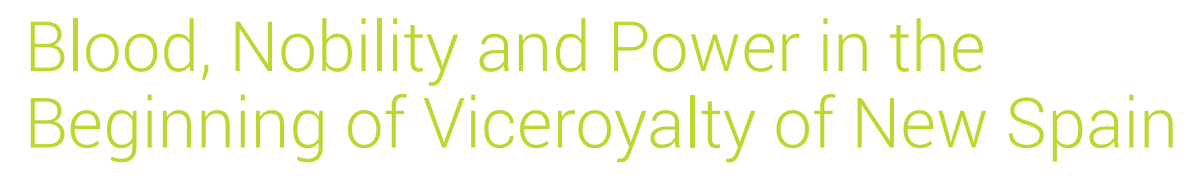

\section{David García Hernán}

Universidad Carlos III de Madrid

ESPAÑA

davidgar@hum.uc3m.es

[Hipogrifo, (issn: 2328-1308), 8.1, 2020, pp. 207-221]

Recibido: 02-09-2019 / Aceptado: 04-12-2019

DOI: http://dx.doi.org/10.13035/H.2020.08.01.15

Resumen. Junto con los elementos culturales, las prácticas y comportamientos sociales castellanos fueron llevados a América desde los primeros momentos de la conquista. En los primeros tiempos del virreinato de Nueva España se pueden ver claramente esas prácticas en lo que se refiere a la consideración de la nobleza de sangre. El presente trabajo analiza la trascendencia del linaje y de la sangre, más allá de los condicionantes étnicos, como fenómeno social en el espacio del actual México. Para ello se centra, a través de ejemplos bien significativos, en los tres grandes grupos tradicionales de división estamental: la baja nobleza (los hidalgos, básicamente), los caballeros y los aristócratas.

Palabras clave. Nueva España; nobleza; hidalgos; caballeros; aristócratas; linaje; sangre; mérito.

Abstract. Castilian social practices and behaviors as well as cultural elements were taken to America from the first moments of the conquest. In the early periods of the Viceroyalty of New Spain these practices could be clearly seen related to the consideration of blood nobility. The present work analyzes the transcendence of lineage and blood, beyond ethnic conditions, as a social phenomenon in the space of the current Mexico. For this target, it focuses on the three large traditional groups of state division: the low nobility (basically the hidalgos), the knights, and the aristocrats. And this scheme is developed underlining some very significant examples.

Keywords. New Spain; Nobility; Nobles; Knights; Aristocrats; Lineage; Blood; Merit. 
Los españoles transmitieron en América desde el primer momento de la colonización, como es bien sabido, no solo el entramado normativo y administrativo castellano (lo que ya de por sí era una labor inmensa de organización de una población de millones de seres y decenas de millones de kilómetros cuadrados), sino también su lengua, su religión, su cultura... Pero un aspecto sobre el que, en nuestra opinión, se ha insistido poco, es la importancia de la transmisión de las costumbres sociales y su reflejo en el marco jurídico en cuanto al hecho fundamental de la jerarquización social estamental, independientemente de los criterios raciales. Particularmente, el relativo a la presencia en América del recurrente debate entre la sangre y el mérito para definir a la "verdadera" nobleza. Un debate que ha tenido su reflejo en los últimos años en la Historiografía en el caso del marco hispánico peninsular ${ }^{1}$, pero que pensamos que requiere también una mirada atenta a la dimensión americana; por lo menos en lo que se refiere a los comportamientos relacionados con la sangre y su categorización social en el espacio indiano, y su relación con la herencia española.

En este caso nos vamos a centrar, dentro de este inmenso universo americano, en el virreinato de Nueva España en sus primeros tiempos; es decir en los siglos XVI y parte del XVII, con unas muestras relativas a la condición de la nobleza de sangre que pensamos que son bien significativas. Sobre todo, porque estos ejemplos son representativas de los tres niveles de nobleza que tradicionalmente se han venido manejando en la historiografía española a partir de las primeras obras de Historia social desde la segunda mitad del siglo pasado, con los trabajos de don Antonio Domínguez Ortiz a la cabeza². Un esquema que, si bien en los últimos años se ha considerado por algunos autores como demasiado tradicional y necesitado de cambios significativos, consideramos que sigue siendo esencialmente válido, sobre todo desde un punto de vista metodológico y explicativo, para mostrar de un modo didáctico las grandes diferencias estamentales existentes entre las condiciones de vida y el marco estatutario de los nobles ${ }^{3}$. Así, a través de estas páginas veremos tres ejemplos muy significativos de otros tres niveles de nobleza (baja, media y alta) con unos comportamientos muy característicos de su respectiva condición nobiliaria.

\section{EL HIDALGO DE SANGRE SANCHO DE CANIEGO}

Los hidalgos castellanos ${ }^{4}$ formaron una parte importante de las huestes de conquista en las Indias, y, por supuesto, en el caso del virreinato de Nueva España. De hecho, según Marchena Fernández, el porcentaje de plebeyos, honrados y hu-

1. Ver, especialmente, García Hernán y Gómez Vozmediano, 2016.

2. Particularmente, una de sus obras más emblemáticas sobre las clases privilegiadas (Domínguez Ortiz, 1973)

3. Para el debate de los últimos años sobre si era estamental o no la sociedad española del Antiguo Régimen, ver García Hernán, 2019.

4. Sigue siendo muy válido y útil para conocer los diferentes tipos de hidalgos, con su complejidad jurídica y social, el libro de varios autores (1989) sobre Hidalgos et hidalguía dans l'Espagne des XVI ${ }^{e}-X V I I I^{e}$ siècles. Téories, practiques et representations. 
mildes no llegaba al 15\%. Hay que tener en cuenta, además, como también señala el mismo autor, que

una vez realizado el trasplante continental, todo el mundo ascendía, al menos un grado, en la jerarquía social, los hidalgos pasaban a considerarse «hidalgos notorios», los «hijos de» intentaban conseguir escudos de armas, constituyendo esa vasta generación de «hidalgos nuevos», y los plebeyos aparecerán como «hijos de» $\mathrm{u}$ «hombres de honra, bienes y fama» 5 .

Muy significativamente, en las presentaciones culturales se llega a asemejar, con evidente hipérbole para atraer la atención y el gusto del lector y/o espectador, la condición de español con la de hidalgo. En Arauco domado por el excelentísimo señor don García Hurtado de Mendoza, de Lope de Vega, por ejemplo, el indio Rengo le dice al indio Tucapel la conveniencia de rendirse a los españoles, entre otras cosas, por su hidalguía:

Confesad su pulicía,

su lenguaje, su hidalguía,

su República, sus leyes;

pues, ¿por qué no han de ser reyes

de cuanto el sol mira y cría? 6

El propio Tirso de Molina destacaba en su Todo es dar en una cosa, de la Trilogía de los Pizarros, que Francisco Pizarro, de niño, quería ya empezar su propio linaje a partir de sus hazañas, aunque aprovechándose -eterna contradicción del orden social del Antiguo Régimen en esa dicotomía entre la sangre y la virtud- de que, aunque natural, era hijo de Gonzalo Pizarro, que tenía sangre noble?

Ya en la vida real, en la Nueva España, el hidalgo Sancho de Caniego, nacido en la Guadalajara peninsular, era alcalde mayor de las minas de Zacatecas. En 1554 se le hizo una residencia por cargos que había contra él por varios excesos que había cometido. Entre otras acusaciones, se decía de él que había mandado prender a varios justicias de la zona sin tener competencia para ello, y haber robado caballos a los indios; además de que se hacía pasar por soltero cuando se sabía que había estado casado en Castilla, en dicha ciudad de Guadalajara. Se decía también por parte de los acusadores que había venido a Nueva España huyendo de delitos cometidos en Guadalajara.

Con objeto de esquivar la prisión, Caniego elevó al juez de residencia una petición para que no estuviera preso debido a su condición de hidalgo notorio, no de privilegio (es decir, hecho hidalgo por el rey, no de sangre); lo que, según él, le eximía de tal aspereza por esa condición de linaje reconocida por el derecho. En dicha petición se decía por parte de su procurador:

5. Marchena Fernández, 1992.

6. Lope de Vega, Arauco domado..., Acto II. Sobre esta pieza como comedia de propaganda nobiliaria, ver Mata Induráin, 2016.

7. Tirso de Molina, Todo es dar en una cosa, Acto, II. 
... que por ser caballero hijodalgo notorio de padres y agüelos y en tal posesión era habido e tenido e comúnmente reputado y como tal había siempre gozado las libertades y preeminencias que gozaban los otros caballeros hijosdalgo, y que como tal se le habían encargado en la ciudad de Guadalajara de los reinos de España pertenecientes los caballeros, y que por tal él no podía estar preso como estaba por deudas que estaban complidas y otras por complir y fianzas que él había hecho. Y así, por esto como por otras cosas que suelen acaecer, que convenía a su derecho que su persona y armas y caballo y casa y servicio della estoviesen libres, por manera que él no pudiese ser preso ni estar como lo está al presente por deudas o bien por las otras cosas susodichas le pudiesen ser ejecutadas... ${ }^{8}$

La importancia de esa diferencia entre la hidalguía de privilegio (la concedida por el rey a partir de unos determinados méritos, de muy diversa condición, de una persona) y la de sangre (la que venía por linaje al interesado y que se transmitía a sus descendientes) era evidente, por lo que, para dirimir esta cuestión, el juez mandó que se llevara a cabo un exhaustivo interrogatorio de testigos.

En dicho interrogatorio, las preguntas giraban esencialmente sobre los ascendientes del acusado, siendo el objeto de la prueba determinar su condición de noble de sangre. El juez de residencia expresaba con claridad cuáles debían ser las preguntas que se debían hacer a los testigos. Unas preguntas, por otro lado, que nos demuestran también con toda claridad la trascendencia de la hidalguía de sangre y los elementos y condiciones fundamentales de dicha condición:

Primeramente sean preguntados si conocen al tal Sancho de Caniego y si conocieron a Juan de Caniego Guzmán y a doña Marina de Gauna Carrillo su mujer, madre y padre del dicho Sancho Caniego, y a Sancho de Caniego... y a doña Marina Beltrán su mujer, difuntos, padre y madre que fueron del dicho Juan de Caniego Guzmán, agüelos del dicho Sancho de Caniego, y si conocieron ... [a] Gutierre de Campuzano y a Marina de Gauna Carrillo, su mujer, difuntos, padres de la dicha doña María de Gauna Carrillo y agüelos del dicho Sancho de Caniego, vecinos todos que fueron de la dicha ciudad de Guadalajara de los reinos de Castilla9 ${ }^{\text {. }}$

Es decir, el interrogatorio se iba a centrar en tres generaciones para comprobar la nobleza de sangre del pretendiente, la de sus abuelos, la de sus padres y la de él mismo. Inmediatamente después había que comprobar su condición de cristiano y de hijo legítimo:

Iten, si saben que los dos, Juan de Caniego Guzmán y doña Marina de Gauna Carrillo su mujer, fueron casados y velados en paz de la madre santa Iglesia y hobieron y procrearon por su hijo legítimo y de legítimo matrimonio nacido al dicho Sancho de Caniego ${ }^{10}$

8. Archivo Histórico Nacional, Sección Nobleza [AHNOB], Casal de Criegos, Caja [C.] 06, Documento [D.]1, fol. 192r. 


\section{A continuación venía la pregunta principal:}

Yten, si saben que el dicho Sancho de Caniego es caballero hombre hijodalgo notorio de solar conocido de padres y agüelos porque él [y sus padres y abuelos] son y fueron caballeros hombres hijosdalgo notorios de solar conocido vecinos de la dicha ciudad de Guadalajara de los reinos de Castilla y como tales de uno, veinte, treinta, cuarenta, cincuenta, sesenta años y más tiempo a esta parte y de tanto tiempo que memoria de hombres no es en contrario en la dicha ciudad de Guadalajara donde moraron siempre ${ }^{11}$.

La condición de hidalgo notorio venía a significar, ante los continuos pleitos de hidalguía (que perjudicaban al pretendiente a la hidalguía de sangre ya sólo por el hecho de tener que demostrarla ante un tribunal, mientras que el notorio -la misma condición lo dice- no) era muy importante por cuanto la hidalguía, también desde el punto jurídico, se fundamentaba en la estimación que hacían de la persona los demás en cuanto a si era integrante o no en el grupo de privilegiados; es decir, si tenía honor estamental ${ }^{12}$. Esa estimación tenía socialmente uno de los testimonios más importantes en el conocimiento por todos los lugareños de una casa señorial familiar, que se identificaba constantemente con el linaje. A los hidalgos de privilegio no se les podía aplicar esa consideración esencialmente por la ausencia del paso del tiempo en su hidalguía ${ }^{13}$.

Y entre los privilegios anejos a la condición de la hidalguía de sangre destacaba el hecho de que sus padres y abuelos no hubieran tenido obligaciones fiscales directas, que no hubieran sido pecheros. Y, así, se continúa en las instrucciones para llevar a cabo el interrogatorio de Sancho Caniego refiriéndose a sus ascendientes:

... que no pecharon ni pagaron ni contribuyeron en ningunos y algunos pechos ni derramas reales ni concejiles en que pechan y trebutan los buenos hombres pecheros a Su Majestad, lo cual es público e notorio, y los testigos lo saben porque lo vieron y oyeron a sus padres y agüelos y mayores y más ancianos y así pasaba y era público e notorio y pública voz y fama... ${ }^{14}$

Y, además, los testigos debían dejar constancia que esa condición de hidalguía se mantuvo en el tiempo sin ninguna excepción:

Iten, si saben que de todo el dicho tiempo a esta parte se puso declarado continuamente en la dicha ciudad de Guadalajara donde los dos sus padres y agüelos del dicho Sancho de Caniego moraron siempre les guardaron e mantuvieron las honras y franquicias y libertades y esenciones que se guardan a los otros hijosdalgo y caballeros, y así administraron los oficios que los caballeros hijosdalgo usaban, por manera que los susodichos siempre de tiempo inmemorial acá esto-

11. AHNOB, Casal de Criegos, C. 06, D.1, fols. 194 v-195r.

12. Para estas cuestiones, sigue siendo fundamental, a pesar del paso de los años, la obra de Maravall sobre el poder, el honor y las elites del siglo XVII, con planteamientos aplicables en su inmensa mayoría a la centuria anterior y aun antes. Maravall, 1979.

13. Ver, igualmente, VV. AA., 1989. Para una visión global y, al mismo tiempo, sintética, García Hernán, 1992. 14. AHNOB, Casal de Criegos, C. 06, D.1, fol. 195r. 
vieron en dicha posesión de caballeros hijosdalgo comúnmente cerca de todos los conocieron, y por esto son y fueron esentos y no por otra causa ni razón alguna, y así es público e notorio y pública voz y fama y los testigos lo saben por cuanto vieron y oyeron ${ }^{15}$.

Además de que, como se ve también en el texto, tenían que haber disfrutado del privilegio de la mitad de oficios como hidalgos de su ciudad.

Al final de todo el proceso, en 1559, la audiencia de la ciudad de Compostela, en Nueva Galicia, dentro de la Nueva España, le daba a Caniego por inocente de los cargos que se le imputaban. Pero, independientemente de la justicia o no de la sentencia, lo que más nos interesa a nosotros para el tema que nos ocupa es la actitud de Sancho Caniego una vez que se vio declarado inocente.

Caniego interpuso entones una querella contra sus acusadores, diciendo que, «siendo él hijodalgo de solares conocido por una y otra línea, ha recibido mayor afrenta» ${ }^{16}$. Lo que, una vez más, nos viene a dar una nueva dimensión de la consideración social de la hidalguía de sangre frente a la de privilegio, hablando de la quiebra del honor estamental. Desde luego, una cosa eran lo que decían los tratadistas nobiliarios acerca de que la verdadera nobleza era la de la virtud personal ${ }^{17}$, y otra muy diferente la realidad social derivada no sólo de toda una cultura en la que primaba la sangre y el linaje ${ }^{18}$, sino también de su reflejo en el derecho. Cuestiones todas estas presente en Castilla y, como se ve, traspasadas a América, concretamente en este caso a la Nueva España, de una forma prácticamente idéntica.

\section{LOS CABALLEROS Y LOS BIENES VINCULADOS}

Como cada vez está poniendo más de relieve la historiografía española de los últimos tiempos, el grupo social de los caballeros tenía gran importancia dentro del espectro social por su peso económico (era, aparte de la condición - cuando la había - de tener o no un hábito de las órdenes militares, la principal distinción con los hidalgos) y por sus significación jerárquica dentro del entramado de redes y clientelas de poder en un marco esencialmente local ${ }^{19}$.

La condición de caballero llevaba aparejado un estatus de riqueza que, por supuesto, influía en muy diversos ámbitos, incluido el de la transmisión patrimonial. Y, desde luego, quien formaba parte de esa elite social y económica (en ocasiones también política) mantenía unos comportamientos que mostraran a la sociedad de

15. AHNOB, Casal de Criegos, C. 06, D.1, fol. 195r.

16. AHNOB, Casal de Criegos, C. 45, D. 6, s. fol.

17. Especialmente, una de las voces más destacadas en este sentido durante en toda la Alta Edad Moderna en España, Luisa María de Padilla, condesa de Aranda, autora de Nobleza virtuosa (1637).

18. García Hernán y Gómez Vozmediano (eds.), 2016.

19. Sobre las órdenes militares y los caballeros de hábito, la bibliografía va siendo cada vez más numerosa. Siguen teniendo vigencia los estudios ya clásicos de Postigo Castellanos, 1987, y Fernández Izquierdo, 1992. Pero en los últimos años, a partir de las nuevas investigaciones, se han abierto muchos caminos, algunos de los más importantes expuestos en el volumen de Rivero Rodríguez (ed.), 2009. 
su tiempo sin ninguna duda su pertenencia a ese grupo, además de recibir las ventajas que de ello se derivaban. No es casualidad que Cervantes reflejara el hecho de las posesiones del caballero del verde gabán en clara comparación desfavorable para don Quijote por su condición de hidalgo frente a la de caballero de aquel tal don Diego de Miranda:

Soy más que medianamente rico y es mi nombre don Diego de Miranda; paso la vida con mi mujer y con mis hijos y con mis amigos; mis ejercicios son el de la caza y pesca, pero no mantengo ni halcón ni galgos, sino algún perdigón manso o algún hurón atrevido. Tengo hasta seis docenas de libros [...]. Alguna vez como con mis vecinos y amigos, y muchas veces los convido; son mis convites limpios y aseados y no nada escasos... ${ }^{20}$

Al igual que ocurría con lo relativo a la hidalguía y su fundamental condición del linaje, en el caso de los caballeros su pautas de actuación (una vez que ellos quedaban fuera de aquel debate de la sangre y el mérito por su estatus superior el del mero hidalgo) se vinculaban más bien a la posesión y la ostentación de la riqueza familiar. Al contrario de aquellos que piensan en nuestros días que la institución jurídico-económica del mayorazgo estaba únicamente relacionada con la alta nobleza y el régimen señorial, muchas familias de niveles más inferiores de nobleza optaban por la perpetuación de su poderío - fuera del nivel que fuera- familiar a partir de esa institución ${ }^{21}$.

Y al igual que como hemos visto para el caso de la hidalguía, esos comportamientos sociales de los caballeros se trasplantaron a América a partir del modelo castellano. En el virreinato de Nueva España en la segunda mitad del siglo XVI se fueron creando mayorazgos por los caballeros peninsulares que habían emigrado a las Indias 22 .

Don Luis de Castilla (como es sabido, aunque hubo notables adulteraciones de la norma, la utilización del don estaba reservado a los caballeros o grupos sociales de mayor jerarquía) era caballero del hábito de Santiago. Junto con su mujer, Juana de Sosa, vincularon por vía de mayorazgo una serie de casas en la ciudad de México, una huerta, una estancia de ganado, tierras de labor en el pueblo de Tacura y otros bienes en favor de su hijo primogénito don Pedro Lorenzo de Castilla. Este último disfrutó de estos bienes vinculados hasta su muerte, sucediéndole en el mayorazgo su hijo mayor don Luis Felipe de Castilla. A la muerte de este la sucesión sería más indirecta y recaería en manos de doña Isabel de Castilla y de Luján. Su padre y legítimo administrador, don Francisco Pacheco de Córdoba y Bocanegra, reclamaría en ciudad de México en 1603 ante el alcalde del crimen y de provincia de dicha ciudad, además de miembro del Consejo Real, el licenciado Gaspar de

20. Cervantes, Don Quijote de la Mancha, p. 664

21. Hernández Franco y Soares da Cunha, 2010. Ver asimismo, para el caso navarro, Usunáriz, 2009; y para el caso valenciano, Catalá Sanz, 2011.

22. Sobre la fundación de mayorazgos en América, como ejemplo de este traslado de instituciones y valores desde la metrópoli, ver, por ejemplo, Cramaussel, 2010; Teruel, 2016; Jiménez Abollado, 2011 a, Jiménez Abollado, 2011 b, y Monegus, 2016. 
Ayala, que se le permitiera a su hija (y de su primera mujer, doña Catalina de Castilla y Chaves) tomar posesión de ese mayorazgo en virtud de ser la nieta mayor y más cercana del mencionado don Pedro Lorenzo de Castilla, vía línea materna.

Para que el alcalde Gaspar de Ayala pudiera ordenar un mandamiento de posesión de dicho mayorazgo, hubo que hacer una información en la cual constara la

Filiación [...] de doña Isabel de Castilla y Luján, poseedora del mayorazgo que fundaron los señores don Luis de Castilla, caballero del hábito de Santiago, y doña Juana de Sosa, sus agüelos 23 .

En el mandamiento de posesión se daba, como es natural, la mayor importancia a las sucesiones familiares a través del linaje:

... bienes vinculados por vía de mayorazgo por don Luis de Castilla y doña Juana de Sosa su mujer en favor de don Pedro Lorenzo de Castilla su hijo, que por su fin y muerte subcedió en él don Luis Felipe de Castilla su hijo, el cual por haber asimismo fallescido y pasado desta presente vida sin dejar hijo ni hija ligítima subcedió en él la dicha doña Isabel de Castilla y de Luján, su hija ligítima [de Francisco Pacheco] y nieta del dicho don Pedro Lorenzo de Castilla, y la información por él [su padre Francisco Pacheco] y los demás recados en esta causa presentados, dijo [el alcalde Gaspar de Ayala] que mandaba y mandó se le libre y despache al dicho don Francisco Pacheco de Bocanegra, como padre y ligítimo administrador de la dicha doña Isabel de Castilla de Luján, su hija mayor, el dicho mandamiento de posesión para que la tome de todos los bienes vinculados en la dicha escriptura de mayorazgo, el cual se le dé sin perjuicio de tercero que mejor derecho a ellos tenga... 24 .

Con el tiempo, al morir sin sucesión la mencionada Isabel de Castilla el mayorazgo pasaría a su hermana doña Catalina de Castilla, que también moriría sin descendencia en la ciudad de Zacatecas.

Como se ve, el mecanismo jurídico del mayorazgo, apuntalado en Castilla por las leyes de Toro de $1505^{25}$, se expresaba en toda su magnitud para un caballero novohispano y sus descendientes, que tuvieron en esa institución, como otros miembros de su clase, una apoyatura firme para la no desmembración ni disolución del patrimonio familiar, transmitido íntegro en lo que se refiere a los bienes vinculados (salvo facultad real en contrario) de generación en generación. La importancia de la sangre era, pues, más que evidente. También en un nivel más alto que el de los hidalgos dentro del estamento nobiliario. 


\section{LA ARISTOCRACIA Y EL PODER DE SU SANGRE}

Los nobles de alto rango, los aristócratas, constituían un grupo social de cuyas filas salieron muchos personajes que desempeñaron los más altos cargos en América; particularmente el más importante, el de virrey ${ }^{26}$. A pesar de que para muchos de ellos dicho cargo conllevaba dificultades que no existían en el ámbito europeo, como la insalvable de la distancia, o la imposibilidad de poder esperar entroncar ni establecer lazos clientelísticos con la nobleza de allí (algo que ocurría con asiduidad en Europa ${ }^{27}$ ), muchos miembros de la alta nobleza optaron por esta vía de poder y ostentación social. En estos casos, la recurrente referencia a la sangre se constituía en un mecanismo de justificación social de la evidente desigualdad y jerarquía. Lo cual, para la perpetuación de este sistema, implicaba una serie de representaciones culturales muy significativas.

En Algunas hazañas de las muchas de don García Hurtado de Mendoza, marqués de Cañete, de Antonio Mira de Amescua y otros autores, sobre la familia del que fuera virrey del Perú a finales del siglo XVI, se pueden leer en boca del indio Colocolo los siguientes versos referidos a los ascendientes de don García:

Don Lope Íñiguez luego pone a raya en Roncesvalles al francés brioso.

El cuarto señor llega a Vizcaya, don Íñigo, su hijo valeroso; éste, en quien Marte su valor ensaya, ganó a Castrogeriz, y al generoso don Íñigo, también López, dio al mundo primer conde de Ordoño rey Segundo. Don Hurtado famoso de Mendoza, primer señor de aquesta casa altiva, sangre y blasones de los reyes goza porque en sangre real su nombre viva: aquí la fama oyendo, se alboroza, al que ilustró la fama furtiva, al que de Cuenca fue por leal acero mayor guarda, y del rey montero 28 .

Aunque todavía de una forma más gráfica nos habla Ercilla en su grandiosa Araucana a propósito del nombramiento de don García Hurtado de Mendoza para capitán general de Chile a partir de su sangre noble:

26. Para los virreyes en la América colonial sigue siendo un referente la obra del mexicano Rubio Mañé, 1959.

27. Por ejemplo, en el caso de Nápoles y su ansiado virreinato, Hernando Sánchez, 1994.

28. Mira de Amescua [y otros autores], Algunas hazañas de las muchas..., Acto I. Ver para esta comedia de nueve ingenios Mata Induráin, 2013. 


\begin{abstract}
A tu hijo, joh marqués!, te demandamos, en quien tanta virtud y gracia cabe, porque con su persona confiamos que nuestra desventura y mal se acabe: de sus partes, señor, nos contentamos, pues que por natural cosa se sabe, y aun acá en el común es habla vieja, que nunca del león nació la oveja29.
\end{abstract}

Pero, volviendo los ojos a Nueva España, vamos a centrar nuestra atención en el virrey don Álvaro Manrique de Zúñiga y Sotomayor. Era comendador de la orden de Santiago, alcalde mayor de Sevilla, y miembro del destacado linaje castellano de los Zúñiga, cuya cabeza más visible era el duque de Béjar, y había servido a Felipe II en algunas destacadas ocasiones cuando en 1585, diez años después de recibir el título del I marqués de Villamanrique, fue nombrado Virrey de Nueva España ${ }^{30}$. Aunque se trataba ya de un cargo bastante importante, sobre todo por lo que tenía de ser el alter ego del rey en los nuevos territorios de la Monarquía en la parte septentrional de las Indias, esto conllevaba la parte negativa de que no solo suponía el distanciamiento de su familia, sino la lejanía física del monarca, con todo lo que eso significaba de alejamiento de los centros de poder. De cualquier forma, era un cargo de altísimo nivel al que pudo optar en gran medida gracias a su sangre aristocrática.

Su nombramiento de virrey se había producido a raíz de la muerte en el cargo de su predecesor, don Lorenzo Suárez de Mendoza Jiménez, conde de la Coruña. Este último había sido sustituido de forma interina por el arzobispo de México, Pedro Moya de Contreras, quien era además, a la sazón, presidente del tribunal de la Inquisición y visitador general del reino. Es decir, un personaje que tenía en sus manos las máximas responsabilidades no sólo civiles sino religiosas (con todo lo que esto representaba en la aplicación de Regio Patronato Indiano) en la Nueva España.

Cuando el nuevo virrey estaba a punto de llegar al destino de su alto cargo, se puso de relieve uno de los comportamientos más genuinos de la alta nobleza relacionados con la posición social que otorgaba la sangre. El protocolo y el ceremonial se constituyeron en un elemento político de condicionante social de primer orden. Las frases que se entrecruzan entre los dos personajes, el nuevo virrey y el obispo ante la nueva situación institucional y de poder son más que elocuentes de la importancia que tienen las fricciones sociales (en algunos casos ridículas para nuestro tiempo) entre personajes del más alto rango social. Merece la pena que nos detengamos en ellas, porque como decimos, hablan por sí solas:

29. Ercilla, La Araucana, Canto XIII.

30. Sobre este importante personaje que, como otros muchos, tuvo que sufrir un duro e injusto proceso esencialmente por los vaivenes de la política y las tensiones jerárquicas sociales, tenemos la reciente tesis doctoral de María Vicens Hualde: Aristocracia y servicio en la monarquía de Felipe II: el marqués de Villamanrique entre Castilla y la Nueva España, 1532-1604, leída en el Departamento de Historia Moderna de la Universidad Autónoma de Madrid en septiembre de 2019. Doy las gracias a la autora por permitirme su lectura antes de su publicación. 
Viniendo navegando el marqués de Villamanrique para la Nueva España desde el cabo de Sancto Antón, despachó una barca al arzobispo de México dándole cuenta de su ida, y porque en la carta le puso muy llustre y no llustrísimo mostró tanta indignación, que aunque el marqués llegó a Sant Joan de Ulúa y estuvo en la Veracruz algunos días malo y en Jalapa más de quince, nunca le respondió ni escribió, antes, habiéndose propuesto en la Real Audiencia de México que, pues habían tenido relación que su virrey estaba malo, era bien y inviarlo a visitar, el arzobispo no quiso venir en ello ni firmar la carta que el audiencia escribió la cual le invió el audiencia con un portero de la sala que se la dio al marqués en persona con aviso de lo que el arzobispo había hecho ${ }^{31}$.

Una discusión trascendental por una cuestión también trascendental...: el tratamiento de «Muy ilustre» en lugar de «llustrísimo». Algo que mueve a risa con nuestros patrones mentales-sociales pero que, como se ve, tuvo sus importantes consecuencias en las relaciones entre los dos personajes más importantes del Virreinato de Nueva España en aquellos momentos. Pero, como era de esperar, la cosa no quedó ahí:

Llegado el marqués a Nuestra Señora de Guadalupe una legua de México el arzobispo le fue a visitar y porque un criado del marqués dijo al paje de falda del arzobispo que la soltase que donde estaba la persona de mi señora la marquesa era descortesía entrar con ella y porque el paje de falda no la quiso soltar el criado se la quiso quitar... 32

Todas estas miserias deparaban las tensiones por la jerarquía social e institucional llevaba consigo en la España y en la América española del Quinientos. Evidentemente, las relaciones entre virrey y arzobispo no hicieron sino empeorar, utilizando, como es bien notorio en el texto y como ha destacado recientemente María Vicens Hualde en su excelente tesis, el ceremonial como arma de guerra ${ }^{33}$.

Además, había cuestiones de fondo muy importantes, como el enfrentamiento que tuvo don Álvaro con encomenderos y mineros por la política virreinal de intentar limitar los abusos a los indígenas. Esto le trajo muchos problemas ya que se le acusó (falsamente) en la corte de provocar una guerra civil, por lo que fue destituido fulminantemente. Siendo ya el nuevo virrey otro aristócrata de sangre de alta alcurnia, como don Luis de Velasco y Castilla, I marqués de Salinas del río Pisuerga, se le hizo a Villamanrique una residencia rigurosísima instruida por su acérrimo enemigo el obispo de Tlaxcala, Diego Romano.

Para su defensa, Villamanrique realizó varios escritos incriminando a quienes eran sus acusadores en cuanto a la falsedad de sus acusaciones. En uno de ellos, conservado en la Sección Nobleza del Archivo Histórico Nacional, pasaba revista detalladamente a los motivos por los que sus diferentes enemigos le acusaban, con algunas informaciones muy significativas. Por ejemplo, con respecto a su acusador Martín de Herrera, natural de Béjar, se decía en el informe del cesado virrey que: 
No ha vivido en México sino de malsín ${ }^{34}$, fuese huyendo de México porque el virrey le quiso prender porque no satisfizo a los indios de Tlaxcala más de veinte mil pesos que les es a cargo, y por ello invió el marqués su carta requisitoria al Real Consejo de Indias y se le embargaron aquí algunos bienes por ello ${ }^{35}$.

Como es evidente, la autoridad que daba la pertenencia al orden social más encumbrado, como el de la aristocracia de sangre, era un apoyo para el mantenimiento de la autoridad y las leyes reales en la Nueva España. Y, aun así, si se tenían lo suficientes enemigos entre las "fuerzas vivas" españolas en el virreinato y en la corte, el juego política podía tener un cariz tremendamente amargo. Villamanrique se tuvo que defender, una por una, de todas sus acusaciones, y también, uno por uno, de quienes buscaban su ruina. En el informe mencionado, como conclusión al mismo, se llega a decir una expresión que denota claramente la importancia de las tensiones políticas dentro de los grupos sociales e individuos más encumbrados. Algo que, por su crudeza y acerbo realismo, y también por no haberlo visto de una forma tan directa en ningún otro sitio, no nos resistimos a dejar de consignar aquí:

Y en resolución, cuando en todos estos no militaran tan evidentes causas para tenellos por sospechosos fuera de la persona del arzobispo y de la de don Luis que tienen diferente estimación y están tan claramente conoscidos por émulos y sospechosos, los demás, aunque no lo fueran, son personas de calidad que con facilidad dirán cualquiera cosa que se les pidiere aunque no sea verdad ${ }^{36}$, y ansí no se debe dar crédito en juicio ni fuera dél... 37.

Realmente, pocos testimonios conocemos de la época donde se ponga de manifiesto de una forma tan explícita la realidad de poder en las redes clientelares y sus cauces de autoridad paralelos, y normalmente clandestinos (de ahí la importancia documental del testimonio), que implican un falseamiento de los mecanismos legales e institucionales, al igual que ocurría en la propia metrópoli38, en la sociedad virreinal.

Y termina el informe-alegato defensivo por parte de Villamanrique, cómo no, haciendo referencia a la importancia de su sangre y de su posición social:

... en caso tan grave como el querer macular la reputación de un virrey hijo de uno de los más principales vasallos que Su Majestad tiene en todos su reinos y a quien siempre a hecho tan grandes mercedes habiéndole fiado un reino tan grande ${ }^{39}$.

Es decir, la primera condición que se expresa entre los méritos alegados en la conclusión final es la de «ser hijo de» (la de la sangre), antes incluso que la de los

34. Delator, soplón.

35. AHNOB, Osuna, C. 3910, D. 129, s. fol.

36. La cursiva es nuestra, por su evidente crudeza y realismo ante la realidad del poder.

37. AHNOB, Osuna, C. 3910, D. 129, s. fol.

38. Como está poniendo de relieve la historiografía ya clásica y la más reciente. Ver Imízcoz Beunza, 1995; Soria Mesa, 2004 y 2007, y Andújar Castillo, 2013, entre otros.

39. AHNOB, Osuna, C. 3910, D. 129, s. fol. 
méritos personales. Un descendiente de un título con grandeza de España, como el de su madre la duquesa de Béjar, y de su padre conde de Belalcázar, no podía tener ese trato.

De cualquier forma, en un primer momento estas informaciones y descargos no le sirvieron. Su enemigos en la corte eran muy poderosos; aunque, al final (en 1598, una vez muerto Felipe II y después de los cambios consiguientes en los personajes de peso en la corte), pudo recuperar su honor y rehabilitar su nombre, aunque no así su hacienda, que le había sido confiscada por este riguroso proceso.

Así pues, para los casos que creemos prototípicos estudiados, pese a las continuas alusiones a que la verdadera nobleza es la de la virtud personal, hemos podido ver que la recurrente presencia del linaje y la sangre como factor de diferenciación social no sólo estuvo presente en España, sino que se puede observar con claridad en la sociedad colonial americana. Al igual que en la Península, parece que la práctica estuvo por encima de las consideraciones del mérito de unos teóricos influidos por el humanismo cristiano renacentista, pero que, en realidad, no pudieron impedir la superioridad de la sangre al menos durante toda la llamada Alta Edad Moderna.

\section{BibliografíA}

Andújar Castillo, Francisco, «Hacerse noble a finales del siglo XVII. Las contradicciones de la jerarquía nobiliaria», en Construyendo historia... Estudios en torno a Juan Luis Castellano, ed. Antonio Jiménez Estrella, Julián José Lozano Navarro, Francisco Sánchez-Montes González y Margarita María Birriel Salcedo, Granada, Universidad de Granada, 2013, pp. 17-29.

Catalá Sanz, Jorge Antonio, «Integridad patrimonial, perpetuidad, memoria: contradicciones de los mayorazgos», Studia historica. Historia moderna, 33, 2011, pp. 61-95.

Cervantes Saavedra, Miguel de, Don Quijote de la Mancha [1605 y 1615], edición del IV Centenario con notas de Francisco Rico, Madrid, Alfaguara, 2004.

Clavero Salvador, Bartolomé, Mayorazgo. Propiedad feudal en Castilla, 1369-1836, Madrid, Siglo XXI de España, 1974.

Cramaussel, Chantal, «Valerio Cortés del Rey, fundador del único mayorazgo de la Nueva Vizcaya en el siglo XVII», Revista de Indias, 70, 2010, pp. 77-100.

Domínguez Ortiz, Antonio, Las clases privilegiadas en el Antiguo Régimen, Madrid, Istmo, 1973.

Ercilla, Alonso de, La araucana [1569], ed. de Isaías Lerner, Madrid, Cátedra, 2011.

Fernández Izquierdo, Francisco, La orden militar de Calatrava en el siglo XVI. Infraestructura institucional: sociología y prosopografía de sus caballeros, Madrid, CSIC, 1992. 
García Hernán, David, La nobleza en la España moderna, Madrid, Istmo, 1992.

García Hernán, David, «El valor de la sangre: marco teórico, representación cultural y realidad social», en Monarquías en conflicto. Linajes y noblezas en la articulación de la Monarquía Hispánica (XV Reunión científica de la Fundación Española de Historia Moderna), ed. José Ignacio Fortea Pérez, Juan Eloy Gelabert González, Roberto López Vela y Elena Postigo Castellanos, Santander, Fundación Española de Historia Moderna / Universidad de Cantabria, 2019, pp. 331-368.

García Hernán, David, y Gómez Vozmediano, Miguel F. (eds.), La cultura de la sangre en el Siglo de Oro. Entre Literatura e Historia, Madrid, Sílex, 2016.

Hernández Franco, Juan, y Soares da Cunha, Mafalda (dir.), Sociedade, familia e poder na Península Ibérica. Elementos para uma História Comparativa, Lisboa, Ediçoes Colibri, 2010.

Hernando Sánchez, Carlos José, Castilla y Nápoles en el siglo XVI: el virrey Pedro de Toledo: linaje, estado y cultura (1532-1553), Valladolid, Junta de Castilla y León, 1994.

Jiménez Abollado, Francisco, Pretensiones señoriales de don Pedro Moctezuma Tlacahuepantzin. Desafíos y vicisitudes de un mayorazgo, 1528-1606. Estudio y fuentes documentales, Hidalgo, Universidad Autónoma de Hidalgo, 2011 a.

Jiménez Abollado, Francisco, «Mercedes y privilegios para consolidar un mayorazgo indiano: de don Pedro Moctezuma Tlacahuepantzin a don Pedro Tesifón Moctezuma, primer conde de Moctezuma (1569-1639)», Boletín Americanista, 63, 2011b, pp. 189-210.

Imízcoz Beunza, José María, «Actores sociales y redes de relaciones en las sociedades del Antiguo Régimen: propuestas de análisis en historia social y política», en Historia a debate. Actas del Congreso Internacional «A historia a debate», celebrado el 7-11 de julio de 1993 en Santiago de Compostela, ed. Carlos Barros Guimerans, Santiago de Compostela, Historia a Debate, 1995, vol. 2, pp. 341-354.

Maravall, José Antonio, Poder, honor y elites en el siglo XVII, Madrid, Siglo XXI de España, 1979.

Marchena Fernández, Juan, Ejército y milicias en el mundo colonial americano, Madrid, Fundación Mapfre, 1992.

Mata Induráin, Carlos, «Algunas hazañas de las muchas de don García Hurtado de Mendoza, marqués de Cañete, comedia genealógica de nueve ingenios», Revista Chilena de Literatura, 85, 2013, pp. 203-227. 
Mata Induráin, Carlos, «Linaje y teatro: Arauco domado de Lope de Vega como comedia de propaganda nobiliaria», en La cultura de la sangre en el Siglo de Oro. Entre Literatura e Historia, ed. David García Hernán y Miguel F. Vozmediano, Madrid, Sílex, 2016, pp. 325-348.

Mira de Amescua, Antonio [y otros autores], Algunas hazañas de las muchas de don García Hurtado de Mendoza, marqués de Cañete [1622], ed. de Francisco José Sánchez García, Alicante, Biblioteca Virtual Miguel de Cervantes, 2014.

Monegus, Margarita, «La transformación de los derechos y privilegios de la nobleza indígena en la época colonial», Arqueología mexicana, 24, 2016, pp. 61-64.

Rivero Rodríguez, Manuel (ed.), Nobleza hispana, nobleza cristiana. La orden de San Juan, Madrid, Polifemo, 2009.

Rubio Mañé, José Ignacio, Introducción al estudio de los virreyes de Nueva España, México, UNAM, 1959.

Padilla, Luisa María de, Nobleza virtuosa, Zaragoza, Imprenta de Juan de Lanaja y Cuartanet, 1637.

Postigo Castellanos, Elena, Honor y privilegio en la Corona de Castilla: el Consejo de las Órdenes y los caballeros de hábito en el siglo XVII, Valladolid, Junta de Castilla y León, 1987.

Soria Mesa, Enrique, «Genealogía y poder: invención de la memoria y ascenso social en la España Moderna», Estudis. Revista de historia moderna, 30, 2004, pp. 21-56.

Soria Mesa, Enrique, La nobleza en la España moderna. Cambio y continuidad, Madrid, Marcial Pons, 2007.

Teruel, Ana A., «El marquesado del Valle de Tojo: patrimonio y mayorazgo. Del siglo XVII al XX en Bolivia y Argentina», Revista de Indias, 76, 2016, pp. 379-418.

Tirso de Molina, Todo es dar en una cosa [1635], Alicante, Biblioteca Virtual Miguel de Cervantes, 2006.

Usunáriz, Jesús M., «Mayorazgo, vinculaciones y economías nobiliarias en la Navarra de la Edad Moderna», lura Vasconiae. Revista de derecho histórico y autonómico de Vasconia, 6, 2009, pp. 383-424.

Vega, Lope de, Arauco domado por el excelentísimo señor don García Hurtado de Mendoza [1625], Alicante, Biblioteca Virtual Miguel de Cervantes, 2002.

Vicens Hualde, María, Aristocracia y servicio en la monarquía de Felipe II: el marqués de Villamanrique entre Castilla y la Nueva España, 1532-1604, tesis doctoral inédita, Madrid, Universidad Autónoma de Madrid (Departamento de Historia Moderna), 2019.

VV. AA., Hidalgos et hidalguía dans l'Espagne des XVIe-XVIIIe siécles. Teories, practiques et représentations, París, CNRS, 1989. 